Gulawentah: Jurnal Studi Sosial

ISSN 2528-6293 (Print); ISSN 2528-6871 (Online)

Vol. 4, No. 2, Desember 2019, Hal 67-73

Tersedia Online: http://e-journal.unipma.ac.id/index.php/gulawentah

\title{
Ritual Ganti Langse di Palenggahan Agung Srigati Alas Ketonggo Ngawi: Studi Makna Simbolik dan Potensinya Sebagai Sumber Ketahanan Budaya
}

\author{
Hanik Masykuriah dan Parji \\ Program Studi Magister Pendidikan Ilmu Pengetahuan Sosial, Universitas PGRI Madiun, \\ Jl. AURI No. 16 Madiun, Indonesia \\ Email: hhmasykuriyah42@gmail.com; parji@unipma.ac.id
}

\begin{abstract}
Abstrak
Penelitian ini bertujuan untuk mendeskripsikan nilai simbolik Ritual Ganti Langse dan potensinya sebagai sumber ketahanan budaya. Studi ini menggunakan pendekatan kualitatif. Objek penelitian ini adalah Ritual Ganti Langse dilaksanakan di Palenggahan Agung Srigati Alas Ketonggo Ngawi. Subjek penelitian adalah masyarakat dan juru kunci Alas Ketonggo. Teknik pengumpulan data menggunakan metode observasi, wawancara, dan dokumentasi. Teknik analisis data menggunakan model interaktif. Hasil penelitian menunjukkan bahwa: (1) Palenggahan Agung Srigati merupakan tempat bertapa Raden Brawijaya V (2) Ritual Ganti Langse dilaksanakan pada bulan Syuro tanggal 14 malam 15. Hal ini bertujuan untuk mengganti kain penutup dari Palenggahan Agung Srigati yang memiliki makna membuka lembaran baru kehidupan serta membersihkan diri dari hal-hal yang dilakukan pada waktu 1 tahun dilalui (5) Nilai yang dapat diambil adalah nilai sejarah, makna simbolik dan sumber ketahanan budaya (6) Nilai-nilai tersebut memiliki potensi sebagai sumber ketahanan budaya yang bisa diwariskan kepada generasi penerus.
\end{abstract}

Kata kunci: Ganti Langse; Simbolik; Ketahanan Budaya

\section{Symbolic Ritual of "Ganti Langse" in Palenggahan Agung Srigati Alas Ketonggo Ngawi: Study of Symbolic Meaning and Its Potential as a Source of Cultural Resilience}

\begin{abstract}
This study aims to describe the symbolic value of the Change Langse Ritual and its potential as a source of cultural resilience. This study uses qualitative methods. The object of this research is the Changing Langse Ritual held at Palenggahan Agung Srigati Alas Ketonggo Ngawi. The research subjects were the community and the caretaker of Alas Ketonggo. Data collection techniques using the method of observation, interviews, and documentation. Data analysis techniques using data reduction, data presentation and drawing conclusions. The results in the field show that: (1) Palenggahan Agung Srigati is a place to meditate on Raden Brawijaya V (2) The Change of Langse Rite is held on Syuro on the night of the 14th night. and cleanse oneself of things done during the past 1 year (5) Values that can be taken are historical values, symbolic meanings and sources of cultural resilience (6) These values have the potential as a source of cultural resilience that can be passed on to future generations.
\end{abstract}

Keywords: Ganti Langse; Symbolic; Source of Cultural Resilience

DOI: 10.25273/gulawentah.v4i2.5521

Copyright ( 2019 Universitas PGRI Madiun

All rights reserved. 


\section{Pendahuluan}

Kajian tentang permasalahan kesadaran kolektif lokal dan identitas nasional dalam era globalisasi sangat relevan diwacanakan (Brata, 2016). Menurut Nadlir (2014) orang tua lebih menghargai budaya lokal dibandingkan dengan generasi mudanya, hal ini terjadi karena dampak akulturasi budaya. Sistem budaya lokal dengan kearifan lokalnya yang selama ini digunakan sebagai acuan pembentukan karakter oleh masyarakat (Suwardani, 2015).

Kebudayaan sebagai cara merasa dan cara berfikir yang menyatakan diri dalam seluruh segi kehidupan kelompok manusia yang membentuk kesatuan sosial dalam suatu ruang dan waktu. salah satu unsur budaya Jawa yang paling menonjol adalah adat istiadat atau tradisi Kejawen. Dasar pemikiran dan sejarah kebudayaan yang khas merupakan kultur Jawa adalah digunakannya simbol-simbol atau lambang-lambang sebagai sarana dan media untuk menitipkan pesan-pesan atau nasehat-nasehat bagi bangsanya. Sejarah Jawa menunjukkan penggunaan simbol-simbol itu dalam tindakan, bahasa, dan religi orang Jawa yang telah digunakannya sejak zaman prasejarah (Herusasoto, 2008). Keunikan sebuah tradisi masyarakat Jawa merupakan tradisi religius yang diwariskan merupakan tradisi religius yang turun temurun.

Menurut Andriani (2018) Alas Ketonggo Srigati masih menyimpan karya lisan yang dipercaya oleh warga dan dilisankan secara turun-temurun, serta masih kental dengan mitosmitos dan tradisi yang dipercaya warga setempat. Sebagai bagian dari sejarah, sastra lisan menyimpan banyak informasi terkait kejadian di masa lampau. Sastra lisan seolah menjadi kebanggaan bahkan identitas masing-masing daerah.Tradisi tersebut merupakan perwujudan dari kepercayaan yang kuat terhadap adat istiadat serta tanggapan masyarakat terhadap kekuatan alam dan kekuatan gaib untuk mengetahui makna yang terkandung didalam upacara. Setiap adat upacara memiliki makna religi bagi para pendukungnya, di mana masyarakat akan mendapatkan rasa aman dan ketenangan batin apabila telah melaksanakannya. Semua adat yang berkembang dalam kehidupan masyarakat sampai sekarang masih dilestarikan, karena di dalamnya terkandung ajaran-ajaran atau pengetahuan yang berisi norma-norma, nilai-nilai dan peraturanperaturan dalam mengatur tingkah laku masyarakat tetap mempunyai kepercayaan terhadap kekuatan gaib (Hanif \& Zulianti, 2012).

Salah satu unsur kebudayaan yang banyak menarik perhatian masyarakat dewasa ini yaitu religi dengan segala manivestasinya. Tradisi keagamaan oleh sebagian besar masyarakat dianggap memegang kunci penting dalam kaitan dengan kehidupan masyarakat. Masyarakat terlihat terus meningkat kesemarakan dan kekhidmatan, baik dalam bentuk ritual adat maupun sosial keagamaan. Semangat menjalani tradisi keagamaan tersebut juga terjadi di kawasan Alas Ketonggo Kabupaten Ngawi Jawa Timur (Nuryani \& Hanif, 2013). Kawasan Alas Ketonggo ini menurut masyarakat Ngawi dan sekitar dianggap sebagai alas angker atau 'wingit'. Di alas ini terdapat Punden Palenggahan Agung Srigati dan petilasan Raja Brawijaya. Pada hari-hari tertentu seperti Jum'at Pon dan Jum'at Legi pada bulan Syuro, Pesanggrahan Srigati banyak dikunjungi dan melaksanakan tirakatan atau semedi untuk ngalap berkah. Masyarakat sekitar Alas Ketonggo tidak hanya "percaya" tetapi juga melakukan "ritual gantilangse" secara turun temurun namun masih banyak diantara mereka yang belum mengetahui nilai-nilai yang terkandung di dalamnya. Padahal setiap proses ritual selalu terjadi pemaknaan simbol-simbol tertentu dalam kandungan nilai-nilai budaya, bahkan menjadi wujud ekspresi yang menonjol dari nilai-nilai budaya. Kebudayaan secara utuh sebenarnya meliputi pola pikir atau mindset suatu masyarakat (tentang segala perikehidupannya di masa lampau, masa kini dan masa depan), yang banyak terekspresikan melalui aneka-ragam ritual keagamaan yang dapat berperan dalam meningkatkan ketahanan budaya. Oleh karena itu penelitian ini perlu dilaksanakan.

\section{Metode Penelitian}

Penelitian ini menggunakan metode kualitatif. Objek penelitian ini adalah Ritual Ganti Langse dilaksanakan di Palenggahan Agung Srigati Alas Ketonggo Ngawi. Subjek penelitian 
adalah masyarakat dan juru kunci Alas Ketonggo. Teknik pengumpulan data menggunakan metode observasi, wawancara, dan dokumentasi (Miles \& Huberman, 2002; Moleong, 2012). Metode pengumpulan data yang digunakan untuk menghimpun data penelitian melalui pengamatan dan pengindraan. Dengan tujuan mendapatkan gambaran yang benar tentang suatu gejala sosial atau peristiwa tertentu yang ada dan terjadi pada suatu lokasi dalam suatu daerah. Teknik analisis data menggunakan reduksi data, penyajian data dan penarikan kesimpulan.

\section{Hasil dan Pembahasan}

Kepercayaan terhadap adanya ritual yang dilaksanakan oleh seluruh pelapisan masyarakat yang terdapat di Desa Babadan Kecamatan Paron Kabupaten Ngawi. Keragaman mata pencaharian masyarakat Desa Babadan Kecamatan Paron Kabupaten Ngawi juga dapat mempengaruhi kepercayaan terhadap adanya ritual yang dilaksanakan di Palenggahan Agung Srigati Alas Ketonggo, karena masyarakat yang memiliki sumber mata pencarian tinggi kurang mempercayai bahwa Ritual Ganti Langse memiliki peran penting di dalam kehidupan dan memiliki pengaruh terhadap keadaan ekonomi seseorang (Heruditya, 2017).

Lokasi Palenggahan Agung Srigati terletak agak jauh dari tempat tinggal warga masyarakat Desa Babadan Kecamatan Paron Kabupaten Ngawi tepatnya di Dukuh Babadan . letak Palenggahan Srigati sangat terjangkau dari warga masyarakat sehingga dapat didatangi kapanpun dan pada saat tertentu. Sejarah Desa Babadan tidak terlepas dari sejarah Masyarakat primitif di Kabupaten Ngawi. Desa ini merupakan awalnya pecahan dari Desa Gentong dan Desa Semen, selain itu disana terdapat Alas atau hutan yang dinamakan dengan Alas Ketonggo. Tempat ini adalah hutan dengan luas 4.846 meter persegi, yang terletak $12 \mathrm{KM}$ arah selatan dari Kota Ngawi, Jawa Timur. Menurut masyarakat Jawa, Alas Ketonggo ini merupakan salah satu dari alas angker atau 'wingit' di tanah Jawa. Kepercayaanya, di tempat ini terdapat kerajaan makhluk halus. Sedangkan satu hutan lainnya yang juga dianggap angker adalah Alas Purwa yang terletak di Banyuwangi, Jawa Timur. Alas Purwa disebut sebagai Bapak, sedangkan Alas Ketonggo disebut sebagai Ibu. Kawasan Alas Ketonggo mempunyai tempat pertapaan, di antaranya Palenggahan Agung Srigati. Semua kisah Spiritual tertuang di Punden Srigati yang terdapat di desa Babatan kec. Paron. Kab. Ngawi. Lokasi Pesanggrahan Srigati yang terletak 12 $\mathrm{km}$ arah barat daya Kota Ngawi, tepatnya di Desa Babadan Kecamatan Paron, dapat ditempuh dengan berbagai macam kendaraan bermotor. Pesanggrahan Srigati merupakan obyek wisata spiritual yang menurut penduduk setempat adalah pusat keraton lelembut / makhluk halus. Dilokasi ini terdapat petilasan Raja Brawijaya. Pada hari-hari tertentu seperti Jum'at Pon dan Jum'at Legi pada bulan Syuro, Pesanggrahan Srigati banyak dikunjungi oleh para pesiarah untuk menyaksikan diselenggarakannya upacara ritual tahunan "Ganti Langse" sekaligus melaksanakan tirakatan / semedi untuk ngalap berkah.

Makna Simbolik Ritual Ganti Langse di Palenggahan Agung Srigati Alas Ketonggo Ngawi merupakan Ritual yang dilaksanakan oleh masyarakat Desa Babadan dengan mengganti kain penutup (mori) dibekas tempat semedi Raden Brawijaya $\mathrm{V}$ yang memiliki makna pembersihan diri masyarakat sekitar dari perbuatan buruk yang dilakukan baik disengaja maupun tidak disengaja selama 1 tahun ini dengan simbol kain kafan (mori), selain itu juga ritual ini dilaksanakan sebagai simbol ucapan syukur atas segala sesuatu yang sudah diberikan dalam menjalani hidup. Ritual Ganti Langse Srigati dilakukan karena bertujuan utuk mengganti penutup di Palenggahan Agung Srigati Alas Ketonggo Ngawi yang memiliki pesan secara tersirat, bertujuan agar kita dapat memperbaiki diri serta mengingat hal apa saja yang dilakukan selama setahun menjalani hidup ini, selain itu juga Ganti Langse sendiri juga mempunyai mengganti kain yang lama dengan yang baru agar kembali menjadi putih dan bersih. Dengan diadakan Ritual Ganti Langse ini diharapkan kita bisa memperbaiki dan mengingat hal apa saja yang telah kita lakukan selama ini dan selalu mengingat bahwa apa saja yang kita lakukan selama didunia ini akan dipertanggung jawabkan nanti pada saat kita tidak ada, namun dengan 
memperingati ritual Ganti Langse ini dapat mempertanggung jawabkan sifat kita yang terdahulu dan diganti dengan yang baru.

Setiap ritual itu pasti memiliki tujuan dan fungsi yang sama seperti Ritual Ganti Langse di Palenggahan Agung Srigati ini juga berfunngsi untuk mengganti penutup di Palenggahan Agung Srigati Alas Ketonggo Ngawi yang memiliki pesan secara tersirat, bertujuan agar kita dapat memperbaiki diri serta mengingat hal apa saja yang dilakukan selama setahun menjalani hidup ini, selain itu juga Ganti Langse sendiri juga mempunyai mengganti kain yang lama dengan yang baru agar kembali menjadi putih dan bersih. Dengan diadakan Ritual Ganti Langse ini diharapkan kita bisa memperbaiki dan mengingat hal apa saja yang telah kita lakukan selama ini dan selalu mengingat bahwa apa saja yang kita lakukan selama didunia ini akan dipertanggung jawabkan nanti pada saat kita tidak ada, namun dengan memperingati ritual Ganti Langse ini dapat mempertanggung jawabkan sifat kita yang terdahulu dan diganti dengan hal-hal yang bisa dikatakan baru.

Ganti Langse atau ganti selambu atau kain berupa mori putih yang difungsikan sebagai penutup Palenggahan Agung Srigati di Alas Ketonggo, Desa Babadan, Kecamatan Paron, Kabupaten Ngawi, Jawa Timur, sebagai tradisi tahunan setiap bulan Muharam/Suro. Ganti Langse atau ganti selambu berupa mori putih yang difungsikan sebagai penutup Palenggahan Agung Srigati di Alas Ketonggo, Desa Babadan, Kecamatan Paron, Kabupaten Ngawi, Jawa Timur, sebagai tradisi tahunan setiap bulan Muharam/Suro. Satu ritual tradisi yang sarat magis tersebut digelar secara khidmat penuh penghayatan diawali dengan penyerahan kain selambu mori warna putih bersih sepanjang 15 meter. Selain itu pula karena anggapan diadakannya ritual ini bahwa petilasan dari Prabu Brawijaya memiliki kekuatan magis yang tidak bisa dilihat oleh kasat mata manusia yang memang tidak dapat merasakan anggapan masyarakat, ritual Ganti Langse memiliki fungsi dan tujuan yang sama mengganti kain penutup dari Palenggahan Agung Srigati Alas Ketonggo dengan kain yang baru hal ini terdapat pesan tersirat dimana kita sebagai manusia harus bisa mengganti dan memperbaiki sifat-sifat serta perilaku maupun tindakan keburukan kita diperbarui menjadi yang baik. Selain itu karena itu merupakan petilasan dari Prabu Brawijaya V yang harus kita lestarikan agar daerah kita memiliki nilai kearifan local yang bisa menarik perhatian warga dari luar daerah.

Berdasarkan penelitan mengenai Ritual Ganti Langse di Palenggahan Agung Srigati Alas Ketonggo Ngawi yang pertama adanya kepercayaan yang turun temurun diwariskan dari nenek moyang serta adat istiadat yang memang sudah dipegang teguh oleh masyarakat Desa Babadan dan tidak bisa ditinggalkan, karena apabila ritual itu tidak dilaksanakan maka mereka akan menerima musibah atau balak yang dapat merugikan warga Desa Babadan, selain itu juga Ritual Ganti Langse dilakukan sebagai symbol pembersihan diri dari segala sifat dan tindakan yang buruk selama setahun. Ritual Ganti Langse merupakan symbol ucapan terima kasih juga kepada Tuhan Yang Maha Esa yang telah memberikan kenikmatan sehingga masyarakat sekitar sebagai symbol terima kasih mereka memberikan sedekah bumi hasil dari pertanian (Chrisdyanto, 2013).

Selain itu pula adanya kepercayaan bahwa Palenggahan Agung Srigati dapat memberikan suatu keuntungan atau mengabulkan keinginan serta harapan. Menurut kepercayaan warga Masyarakat Alas Ketonggo bahwa apabila seseorang memiliki keinginan dengan mendatangi dan diberikan kain bekas penutup Palenggahan Agung Srigati itu dapat dikabulkan. Namun kepercayaan masyarakat Desa Babadan apabila tidak diadakan ritual Ganti Langse serta diiringi Tari maka dapat memberikan suatu musibah seperti gagal panen, wabah penyakit, kekeringan dan masih banyak lagi. Ganti Langse atau ganti selambu berupa mori putih yang difungsikan sebagai penutup Palenggahan Agung Srigati di Alas Ketonggo, Desa Babadan, Kecamatan Paron, Kabupaten Ngawi, Jawa Timur, sebagai tradisi tahunan setiap bulan Muharam/Suro. Ritual pertama yang dilaksanakan adalah dengan membawa gunungan terbuat dari hasil panen warga masyarakat sekitar Desa Babadan yang memiliki makna sebagai wujud syukur kepada Tuhan yang telah memberikan hasil panen yang melimpah. Hasil panen serta kain mori dibawa oleh Juru Kunci yang akan diganti dan diarak menuju Palenggahan 
Agung Srigati dengan diiringi oleh juru kunci, perangkat desa, warga masyarakat Desa Babadan serta pendekar dari seluruh persilatan.

Usai diarak sampai Palenggahan Agung Srigati, kain yang digunakan untuk menutup Palenggahan Agung Srigati dagnatikan oleh yang baru dengan iringan Tari Bedhaya yang memiliki makna Penari yang membawakan tarian ini berjumlah sembilan yang menyimbolkan bahwa manusia harus dapat menutup 9 lubang dalam badan manusia agar dapat menyucikan badan. Kesembilan lubang tersebut adalah: dua mata, dua lubang hidung, dua lubang telinga, mulut, anus dan lubang seks. Jumlah sembilan juga merupakan simbol keberadaan alam semesta dengan segala isinya, meliputi matahari, bintang, bulan, angkasa (langit), bumi (tanah), air, angin, api, dan makhluk hidup yang ada di dunia.

Tari Bedhaya erat hubungannya dengan kesakralan. Tarian ini dianggap sebagai ciptaan Kanjeng Ratu Kidul sehingga dianggap sakral. Orang-orang percaya bahwa pencipta tari ini akan senantiasa hadir ketika Bedhaya Ketawang ditarikan dan ikut menari (Ardyanti, 2018). Bahkan, ketika latihan pun Kanjeng Ratu Kidul sering membetulkan kesalahan yang dibuat penari. Kehadiran beliau tidak setiap orang dapat melihatnya, hanya penari yang bersangkutan yang dapat merasakannya. Tari Bedhaya erat hubungannya dengan religiusitas. Semula, Bedhaya Ketawang dipercaya sebagai tarian untuk pemujaan di candi-candi dengan suasana yang religius (Kusumaningrum, 2016). Acara yang paling ditunggu-tunggu yakni Ganti Langse dilakukan oleh para tokoh masyarakat dalam hal ini para perangkat Desa Babadan kurang lebih selama 15 menit. Kemudian Langse/mori yang sudah diganti diserahkan kembali kepada juru kunci untuk dibagikan kepada warga masyarakat yang membutuhkan. Ritual selanjutnya berupa bancaan atau biasa dikenal dengan kalimat 'Slametan' merupakan persembahan doa kepada Tuhan Yang Maha Esa yang dipimpin pemangku adat setempat. Dalam slametan ini dihidangkan berbagai makanan dan jajanan pasar. Untuk makananya dimulai tumpeng, urapurap, bubur sengkolo, bubur merah putih, serta aneka ragam polo pendem. Sedangkan jajanan pasar ada tujuh jenis yang mewakili filosofi sebuah harapan pitulungan atau pertolongan yang berasal dari Tuhan yang Maha Esa. Urap-urap memiliki symbol membaur atau bersatu padu serta menjadi manusia yang berguna dan bermanfaat antara satu dengan yang lainnya.

1. Tumpeng

Tumpeng pungkur berupa nasi yang berbentuk gunungan kemudian di belah menjadi dua dari pucuk sampai dasar kemudian diletakan pada posisi bertolak belakang atau saling ungkur-ungkuran. Tumpeng ini dilengkapi dengan jangan adem atau sayuran yang tidak pedas kemudian dilengkapi pula dengan ur urapan atau gudangan,tetapi tidak menggunakan kecambah atau tauge, kangkung serta daun jlengor. Tumpeng jenis ini melambangkan perpisahan antara orang yang telah meninggal dengan orang yang masih hidup. Orang yang sudah meninggal bakal berada di dalam ahirat, sementara orang yang masih hidup tetap berada di alam dunia. Tumpeng pungkur jika dimaksudkan agar orang yang mengadakan selamatan terbebas dari segala pengaruh jahat atau sebagai tolak-bala, sehingga situasi keluaraga senantiasa adam ayem. Urap-urap memiliki symbol membaur atau bersatu padu serta menjadi manusia yang berguna dan bermanfaat antara satu dengan yang lainnya.

2. Ingkung

Ingkung diartikan untuk menyucikan orang yang mempunyai hajat maupun tamu yang hadir dalam acara selamatan tersebut. Uborampe ini berupa ayam kampung yang dimasak utuh dan di beri bumbu opor, kelapa dan daun salam. Ingkung ini biasanya diletakkan diatas nasi uduk.ingkung ini melambangkan bayi yang belum dilahirkan dengan demikian belum mempunyai kesalahan apa-apa masih suci. Atau dimaknai juga sikap pasrah dan menyerah atas kekuasaan Tuhan. Orang jawa mengartikan kata "ingkung" dengan pengertian di banda atau di belenggu.

\section{Bubur Merah Putih}


Melambangkan keberanian dan kesucian. Di samping itu bubur merah untuk memule atau tanda bakti kepada roh dari bapak atau roh laki-laki dan bubur putih sebagai tanda bakti kepada roh dari ibu atau roh perempuan. Secara komplitnya adalah sebagai tanda bakti kepada bapa angkasa ibu pertiwi atau penguasa langit dan bumi, semua dibekteni dengan harapan akan memberikan berkah, baik kepada si mati maupun kepada yang masih hidup.

4. Jajanan Pasar

Ada tujuh jenis yang mewakili fiosofi sebuah harapan pitulungan atau pertolongan yang berasal dari Tuhan Yang Maha Esa. Urap-urap memiliki simbol membahur atau bersatu padu serta menjadi manusia yang bermanfaat antara satu dengan yang lain.

5. Kain Mori

Kain mori melambangkan kesucian hati dan pikiran yang bersih dari sifat curiga, selain itu juga kain mori melambangkan mengganti lembaran hidup yang baru selama setahun dihadapi. Selain itu juga kain mori memiliki makna sebagai symbol pembersihan diri dari segala sifat dan tindakan yang buruk selama setahun.

Selambu mori itu diserahkan oleh juru kunci Alas Ketonggo kepada tokoh masyarakat. Prosesi penyerahan selambu mori sendiri diiringi sebuah Tari Srigati yang dilakukan 8 penari yang masih gadis/perawan agar tercipta tari yang indah, luwes dan anggun pada saat prosesi tradisi dilakukan atau disebut dengan Tari Bedhaya yang memiliki makna Penari Bedhaya Ketawang mengenakan pakaian pengantin basahan Surakarta. Penari yang membawakan tarian ini berjumlah sembilan yang menyimbolkan bahwa manusia harus dapat menutup 9 lubang dalam badan manusia agar dapat menyucikan badan. Kesembilan lubang tersebut adalah: dua mata, dua lubang hidung, dua lubang telinga, mulut, anus dan lubang seks. Jumlah sembilan juga merupakan simbol keberadaan alam semesta dengan segala isinya, meliputi matahari, bintang, bulan, angkasa (langit), bumi (tanah), air, angina, api, dan makhluk hidup yang ada di dunia (Fitriyani, Andayani, \& Sumarlam, 2017; Hastarini, 2011). Bedhaya memiliki sembilan penari yang masing-masing mempunyai peran sebagai batak endhel ajeg, dhada, gulu, apit ngarep, apit buri, endhel weton, apit meneng, dan boncit. Pergelaran tari ini dapat diartikan sebagai upaya mengharmonisasikan makrokosmos dengan mikrokosmos. Tari Bedhaya Ketawang memiliki beberapa tata rakit, seperti pola lantai rakit lajur, iring-iringan, ajengajengan, lumebet lajur, endhel-endhel apit medal, dan rakit tiga-tiga. Penari endhel ajeg disimbolkan nomor 1, batak disimbolkan nomor 2, gulu disimbolkan nomor 3, dhada disimbolkan nomor 4, boncit disimbolkan nomor 5, apit ngarep disimbolkan nomor 6, apit buri disimbolkan nomor 7, endhel weton disimbolkan nomor 8, dan apit meneng disimbolkan nomor 9 (Andriani, 2018; Fitriyani et al., 2017; Hastarini, 2011).

\section{Simpulan}

Ritual Ganti Langse di Palengahan Agung Srigati Ritual Ganti Langse di Palenggahan Agung Srigati Alas Ketonggo merupakan ritual yang dilakukan dimana mengganti Langse atau penutup dari Pelanggahan Agung Srigati yang dilakukan pada bulan Muharram, selain itu juga Ritual Ganti Langse Alas Ketonggo ini diikuti oleh seluruh lapisan masyarakat desa Babadan Kecamatan Paron Kabupaten Ngawi. Mereka juga sangat mempercayai adanya penunggu dari Palenggahan Agung Srigati yang harus dihormati, walaupun sudah memasuki era modern namun masyarakat Desa Babadan masih tetap melaksanakan ritual Ganti Langse. Hal ini berbeda dilakukan oleh warga masyarakat Desa Babadan masih tetap mendatangi Palenggahan Agung Srigati Alas Ketonggo karena kepercayaan mereka terlalu tinggi terhadap tempat ini. Beliaupun juga mempercayai adanya kekuatan magis yang terdapat di Alas Ketonggo yang mampu membuat ketentraman serta keamanan warga Desa Babadan. Selain itu juga terdapat penunggu di Palenggahan Agung Srigati Alas Ketonggo juga dapat melindungi warga masyarakat Desa Babadan.

Selain itu juga Ritual ganti Langse di Palenggahan Agung Srigati merupakan warisan leluhur yang sampai sekarang masih dilaksanakan, selain untuk menjaga masyarakat dari segala marabahaya ritual Ganti Langse juga merupakan salah satu warisan yang harus dipegang teguh 
dan dipelihara agar budaya yang sudah ada sejak dahulu masih digunakan sampai saat ini. Di era modernisasi ini juga banyak orang-orang yang mempercayai adanya mitos serta kepercayaan terhadap suatu benda maupun ritual tolak musibah (Balak). Sama halnya yang dilakukan oleh warga masyarakat Desa Babadan Kecamatan Paron Kabupaten Ngawi yang masih menjaga dan melaksanakan warisan leluhur dengan melakukan ritual Ganti Langse untuk menghindarkan dari marabahaya, membersihkan diri serta ucapan syukur kepada Tuhan melalui media Palenggahan Agung Srigati, warisan budaya yang masih dijaga ditengah era globalisasi yang mana orangorang berfikir menggunakan logika dibandingkan dengan melaksanakan suatu budaya.

\section{Daftar Pustaka}

Andriani, F. (2018). Mitos Alas Ketonggo Srigati (Petilasan Prabu Brawijaya V) Di Desa Babadan, Kecamatan Paron, Kabupaten Ngawi (Kajian Struktur, Fungsi, Nilai Budaya, Dan Pengaruh). BAPALA, 5(1).

Ardyanti, D. (2018). Ekspresi Verbal dan Nonverbal dalam Upacara Ganti Langse Palenggahan Ageng di Alas Srigati Desa Babadan, Kecamatan Paron, Kabupaten Ngawi (Suatu Kajian Etnolinguistik).

Brata, I. B. (2016). Kearifan budaya lokal perekat identitas bangsa. Jurnal Bakti Saraswati $(J B S), 5(1)$

Chrisdyanto, F. S. (2013). Makna Filisofis Sajrone Tradhisi Ganti Langse ing Petilasan Prabu Kertabumi. BARADHA, 1(3).

Fitriyani, N. H., Andayani, A., \& Sumarlam, S. (2017). Makna Tari Bedhaya Ketawang sebagai Upaya Pengenalan Budaya Jawa dalam Pembelajaran BIPA. Paper presented at the Proceedings Education and Language International Conference.

Hanif, M., \& Zulianti, Z. (2012). Simbolisme Grebeg Suro di Kabupaten Ponorogo. AGASTYA: JURNAL SEJARAH DAN PEMBELAJARANNYA, 2(1).

Hastarini, A. D. (2011). Pergeseran tari bedhaya ketawang (Pergeseran dan Perubahan Tari Bedhaya Ketawang Setelah Keraton Bergabung Dengan NKRI).

Heruditya, A. H. (2017). MEDITASI SETYO HAJAR DEWANTORO (KAJIAN FILSAFAT KEBATINAN JAWA).

Herusasoto, B. (2008). Simbolisme Jawa. Yogyakarta: Ombak.

Kusumaningrum, R. (2016). Fungsi Tari Bedhaya Srigati dalam Upacara Ganti Langse di Desa Babadan Kabupaten Ngawi. INSTITUT SENI INDONESIA (ISI) SURAKARTA,

Miles, M. B., \& Huberman, A. M. (2002). The qualitative researcher's companion: California: Sage Publications.

Moleong, L. J. (2012). Metodologi penelitian kualitatif. Bandung: Remaja Rosdakarya.

Nadlir, M. (2014). Urgensi Pembelajaran Berbasis Kearifan Lokal. Jurnal Pendidikan Agama Islam (Journal of Islamic Education Studies), 2(2), 299-330.

Nuryani, A., \& Hanif, M. (2013). Studi Sosio Religi Wisata Alas Ketonggo Desa Babadan Kecamatan Paron Kabupaten Ngawi. AGASTYA: JURNAL SEJARAH DAN PEMBELAJARANNYA, 3(02).

Suwardani, N. P. (2015). Pewarisan nilai-nilai kearifan lokal untuk memproteksi masyarakat Bali dari dampak negatif globalisasi. Jurnal Kajian Bali (Journal of Bali Studies), 5(2). 